\title{
Sleep SAAF: a responsive parenting intervention to prevent excessive weight gain and obesity among African American infants
}

\author{
Justin A. Lavner ${ }^{1 *}$ (D, Brian K. Stansfield ${ }^{2}$, Steven R. H. Beach ${ }^{3}$, Gene H. Brody ${ }^{4}$ and Leann L. Birch ${ }^{5}$
}

\begin{abstract}
Background: Responsive parenting interventions that shape parenting behaviors in the areas of sleep and soothing, appropriate and responsive feeding, and routines represent a promising approach to early obesity prevention and have demonstrated effectiveness in our previous trials. However, this approach has yet to be applied to the populations most at-risk for the development of early obesity, including African Americans. The Sleep SAAF (Strong African American Families) study is a two-arm randomized controlled clinical trial evaluating whether a responsive parenting intervention focused on promoting infant sleeping and self-soothing can prevent rapid weight gain during the first 16 weeks postpartum among first-born African American infants. The responsive parenting intervention is compared to a child safety control intervention.

Methods: Three hundred first-time African American mothers and their full-term infants will be enrolled from one mother/baby nursery. Following initial screening and consent in the hospital, mothers and infants are visited at home by Community Research Associates for data collection visits at 1 week, 8 weeks, and 16 weeks postpartum and for intervention visits at 3 weeks and 8 weeks postpartum. The primary study outcome is a between-group comparison of infant conditional weight gain (CWG) scores from 3 weeks to 16 weeks; additional weight-related outcomes include differences in change in infants' weight for age over time and differences in infants' weight outcomes at age 16 weeks. Several other outcomes reflecting infant and maternal responses to intervention (e.g., sleeping, soothing, feeding, maternal self-efficacy, maternal depressive symptoms) are also assessed.
\end{abstract}

Discussion: The Sleep SAAF trial can inform efforts to prevent rapid weight gain and reduce risk for obesity early in the lifespan among African Americans.

Trial registration: NCT03505203. Registered April 3, 2018 in clinicaltrials.gov.

Keywords: Rapid weight gain, Obesity, Prevention, Infancy, Responsive parenting, African Americans

\section{Background}

Racial disparities in obesity begin early in development and continue throughout the lifespan [1,2]. From birth to 2 , the prevalence of high weight for length (above the 95th percentile) is $25 \%$ higher among African American children compared to White children [1]. From age 2-19, the rate of obesity is more than $50 \%$ higher among African American children compared to White children [3].

\footnotetext{
* Correspondence: lavner@uga.edu

${ }^{1}$ Department of Psychology, University of Georgia, Athens, USA

Full list of author information is available at the end of the article
}

Similar disparities persist into adulthood: rates of obesity are approximately $25 \%$ higher among African American adults compared to White adults [1]. Differences in early rapid weight gain during infancy (RWG) may be a key driver of these disparities: RWG is one of the most consistent factors associated with later overweight and obesity [2, 4-14], is more common among African American infants than among White infants $[2,15]$, and accounts for more than $70 \%$ of the difference between White and Black children's BMI z scores during early childhood [2].

(c) The Author(s). 2019 Open Access This article is distributed under the terms of the Creative Commons Attribution 4.0 International License (http://creativecommons.org/licenses/by/4.0/), which permits unrestricted use, distribution, and 
The higher prevalence of RWG and actual childhood obesity rates among African Americans suggest that intervening early in development has great potential to significantly reduce risk of later childhood and adult obesity among this population. Interventions that shape parenting behaviors in the areas of sleep and soothing, appropriate and responsive feeding, and routines have been cited as being of particular promise in early obesity prevention [16] and have demonstrated effectiveness in our previous trials [14, 17-19]. However, these interventions have yet to be tested among African American mothers and their infants [16].

Sleep SAAF is a prospective, two-arm, randomized controlled clinical trial evaluating whether a responsive parenting intervention focused on promoting infant sleeping and self-soothing can prevent rapid weight gain during the first 16 weeks postpartum among first-born African American infants. The responsive parenting intervention is being compared to a child safety control intervention. The responsive parenting intervention addresses infant sleep, soothing/crying, and feeding during the first months of life. The safety intervention addresses safe sleep practices as well as other aspects of newborn safety (e.g., food safety, preventing falls, poison prevention, preventing burns, car seat safety). The interventions are delivered at participants' homes by Community Research Associates (CRAs), who are African American community members from communities similar to the ones in which we are implementing the intervention.

\section{Conceptual framework}

Sleep SAAF's responsive parenting intervention is grounded in the developmental literature on parenting sensitivities, arguing that parenting that is developmentally appropriate, prompt, and contingent on the infant's needs [20] can increase infant sleep and selfregulation, and reduce rapid infant weight gain. The intervention is focused on a critical developmental period when plasticity is high. How parents put their infant to bed (e.g., bedtime routines, falling asleep independently) and respond to nighttime awakenings represent important sources of variability in infants' developing sleep patterns $[21,22]$. Because infant sleep bouts are interrupted by waking to be fed, the routines parents establish around sleep can also affect feeding frequency and energy intake, with important consequences for infant weight gain. Similarly, how parents respond to infant crying represents an important source of variability in infants' developing regulation skills; avoiding the use of feeding as the first response to infant distress by using alternative soothing strategies can increase parental responsiveness to infants' needs and promote infants' selfregulation.
Individual and contextual stressors are common among African American mothers and have the potential to affect intervention effectiveness. For example, depressive symptoms are prevalent among African American mothers of infants [23] and are likely to interfere with maternal responsiveness [24]. The broader social context is also likely to pose challenges [25]. The families participating in Sleep SAAF live in communities in Georgia where poverty rates are high and unemployment rates are above the national average [26]. Under conditions of economic distress, parents are vulnerable to anger, low frustration tolerance, and depressive symptoms [27-30], all of which may be consequential for responsive parenting. African American families living in the South must also contend with race-based stressors such as racial discrimination, with negative consequences for depressive symptoms, health, and responsive parenting [31-35]. Lastly, many African American mothers do not have a steady romantic partner at the time of their infant's birth [36], potentially limiting available social support and increasing parenting stress [37]. We examine each of these stressors as moderators of program effectiveness. Our conceptual framework is shown in Fig. 1.

\section{Evidence from previous trials}

Sleep SAAF builds on our two previous RCTs providing evidence for the efficacy of a responsive parenting program. In a pilot study, Birch and colleagues developed and evaluated the SLIMTIME intervention for primiparous mothers who intended to breastfeed [19]. Participants were predominantly middle income and White. The first component of SLIMTIME, "Soothe/Sleep," began when infants were 2-3 weeks old and focused on promoting aspects of responsive parenting to promote the development of infant self-soothing and longer sleep duration and to reduce feeding frequency. As predicted, there was evidence of changes in sleeping, feeding, and soothing as a result of the intervention $[19,38]$. Infants whose mothers participated in the Soothe/Sleep intervention slept longer at night, had fewer total daily feeds, and had fewer nocturnal feeds from age 3 to 16 weeks compared to control group infants. Infants who received the intervention also gained weight more slowly over the first year, indicating that intervening on sleep and soothing behaviors can reduce the rate of weight gain during infancy.

In a subsequent larger scale randomized controlled trial (INSIGHT), the sample included primiparous mothers intending to formula feed as well as those intending to breastfeed and was predominantly middle income and White [39]. This comprehensive responsive parenting program addressed infant feeding, sleeping and soothing, active social play, emotion regulation, and growth record education, and was taught to mothers at 


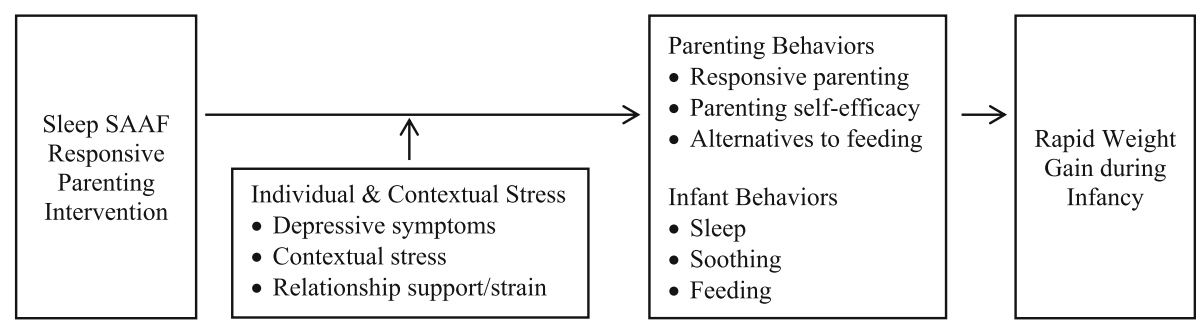

Fig. 1 Early factors affecting rapid weight gain among African American infants

four home visits at 2-, 16-, 28-, and 40 weeks. During the first 16 weeks, program content focused on soothing, sleeping, and breast or bottle feeding; after 16 weeks, the focus was expanded to include introducing solids, table foods, and active social play. Relative to a home safely control, infants in the responsive parenting condition gained weight more slowly than control group infants from birth to 6 months, had lower weight-for-length percentiles at 1 year, were less likely to be overweight at 1 year, and had lower BMI z-scores through age $3[14,17]$. There were also positive sleep outcomes: infants in the responsive parenting condition had longer nighttime sleep duration, more consistent bedtime routines, and earlier bedtimes, and were more likely to self-soothe to sleep without being fed at 8-, 16- and 40 weeks of age [18].

\section{Study aims and hypotheses}

Sleep SAAF builds on the efficacy of these multicomponent responsive parenting programs. Focusing on the initial soothe/sleep component of SLIMTIME and INSIGHT, we test whether a responsive parenting program can promote infants' sleep and self-soothing and reduce rapid weight gain during the first 16 weeks of life among African American infants born in the South. Our specific aims are:

1) To assess the effects of responsive parenting, focused on infant sleep and soothing, on reducing RWG from 3 weeks to 16 weeks among African American infants. We hypothesized that infants in the responsive parenting condition relative to safety control would show less rapid growth from 3 weeks to 16 weeks.

2) To assess effects of responsive parenting on parental and infant behaviors at age 8 weeks, and whether these mediate effects on infant growth from 3 to 16 weeks. We hypothesized that compared with control mothers, mothers in the responsive parenting condition would report higher levels of responsive parenting, parenting selfefficacy, and greater use of alternatives to feeding to soothe, and lower levels of feeding to soothe at 8 weeks postpartum; infants in the responsive parenting condition would have longer sleep bouts and fewer feedings at age 8 weeks. These outcomes would be linked to healthier patterns of weight gain from 3 weeks to age 16 weeks.

3) To examine moderation of intervention effects by individual and contextual factors. We examined whether individual and contextual factors common among African American mothers moderated the effectiveness of the responsive parenting intervention, increasing our understanding of how these stressors affect the ability of high-risk samples to benefit from preventive intervention.

\section{Methods/design}

Overall study design

Sleep SAAF is a two-arm randomized, controlled clinical trial evaluating the effectiveness of a responsive parenting intervention relative to a child safety control. Following initial screening and consent in the hospital by the project's Recruitment Coordinator, mothers and their infants were visited at home by CRAs at 1 week, 3 weeks, 8 weeks, and 16 weeks postpartum for intervention and data collection visits (Fig. 2). To minimize bias during the assessments, separate CRAs completed the intervention visits (at 3 weeks and 8 weeks) and data collection visits (at 1 week, 8 weeks, and 16 weeks). Further, CRAs were trained in (and subsequently delivered) only one of the two study interventions (responsive parenting or child safety).

Funding for this project comes from the National Institute of Diabetes and Digestive and Kidney Diseases (NIDDK; R01DK112874) and the study was registered on www.clinicaltrials.gov (NCT03505203) on April 3, 2018. This study was approved by the Augusta University Institutional Review Board and overseen by a Data Safety Monitor, based on NIDDK guidelines that a Data Safety Monitor is more appropriate for single-site clinical trials that are not masked and are minimal risk, as is the case in the current study. Additional details on the Data and Safety Monitoring Plan are provided in Additional file 1. 


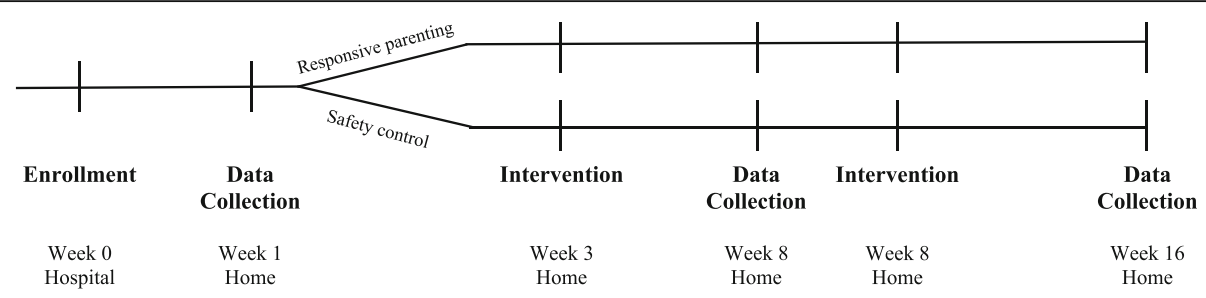

Fig. 2 Sleep SAAF study visit schedule

\section{Participants and recruitment}

A total of three hundred African American motherinfant dyads will be recruited from the mother/baby nursery at Augusta University Medical Center (AUMC) in Augusta, GA. Recruitment began in the spring of 2018 and will continue through the summer of 2021. AUMC provides comprehensive medical care for the Augusta area and serves as a referral center for the state of Georgia and western South Carolina. All newborns delivered at AUMC were screened for participation. The project's Recruitment Coordinator had access to electronic medical records systems in order to pre-screen mothers and infants based on the following criteria: (1) full-term infants ( $\geq 370 / 7$ weeks gestational age), (2) singleton infant; (3) infant $>2500 \mathrm{~g}$ at birth; (4) primiparous mother $\geq 17$ years of age, (5) mother selfidentifying as African American; (6) residence $\leq 75$ miles from Augusta; and (7) English speaking. In addition, mother-infant dyads were excluded if there was a congenital anomaly or neonatal physical or metabolic condition that would significantly affect the newborn's feeding or growth (e.g. cleft palate, complex congenital heart disease); if there were major maternal morbidities or pre-existing conditions that would affect postpartum care or the mother's ability to care for her newborn (e.g., narcotic drug use, uncontrolled depression causing social service contact); if there was a plan for the newborn to be adopted; or if the family planned to move from the area within four months of delivery.

\section{Randomization}

Participants were randomized to either the responsive parenting intervention or child safety control after completion of the 1-week data collection visit, stratifying on sex-specific birth weight for gestational age $(<50$ th percentile or $\geq 50$ th percentile) [40] and intended feeding mode (breastfeeding or formula). Randomization was done using a secure Microsoft Excel application prepared by a statistician unaffiliated with the study and administered by the study's Project Coordinator. Blinding was maintained after allocation only for the CRAs completing the data collection visits. Participants were made aware of their condition, CRAs serving as intervention facilitators were aware of condition because they were only trained in one of the two interventions (responsive parenting or child safety), and study investigators and other project staff (e.g., Project Coordinator, Intervention Coordinator) were aware of condition.

\section{Responsive parenting intervention}

The responsive parenting intervention focused on responsive parenting in the context of (1) sleeping, (2) crying, (3) feeding, and (4) playing (Fig. 3). These topics were introduced and discussed in detail at the first intervention visit at 3 weeks postpartum and reviewed at a booster session at 8 weeks postpartum. All materials were tailored for African American families.

\section{Sleeping}

We provided information about normal sleep patterns in infants, including how many hours of sleep infants typically need and frequency of night waking [41]. We also provided guidance on establishing a consistent bedtime routine that includes putting the infant to bed early, drowsy but awake, and avoiding feeding the infant to sleep or putting the infant to bed with a bottle. We also discussed "dream feeds," where the mother wakes the baby to feed before the mother goes to bed. We briefly addressed safe sleep strategies to prevent Sudden Infant Death Syndrome (SIDS) using materials from the National Institute of Child Health and Human Development (NICHD) [42]. This guidance included always placing baby on her back, on a firm sleep surface, not smoking around baby, keeping baby's sleep area close to, but separate from, where mother and others sleep, and avoiding the use of pillows and blankets.

\section{Crying}

Guidance on crying included information on reasons for infant crying, that crying does not always indicate hunger, how to discriminate hunger from other reasons for infant crying, and how to use alternative soothing strategies other than feeding. Specifically, mothers learned various reasons why babies cry (e.g., wet, cold, hot, tired, gassy, over-stimulated) and that these cries differ in systematic ways, and viewed video clips illustrating these differences. Mothers were also taught soothing strategies that they could use to soothe their crying baby, including Shushing, 


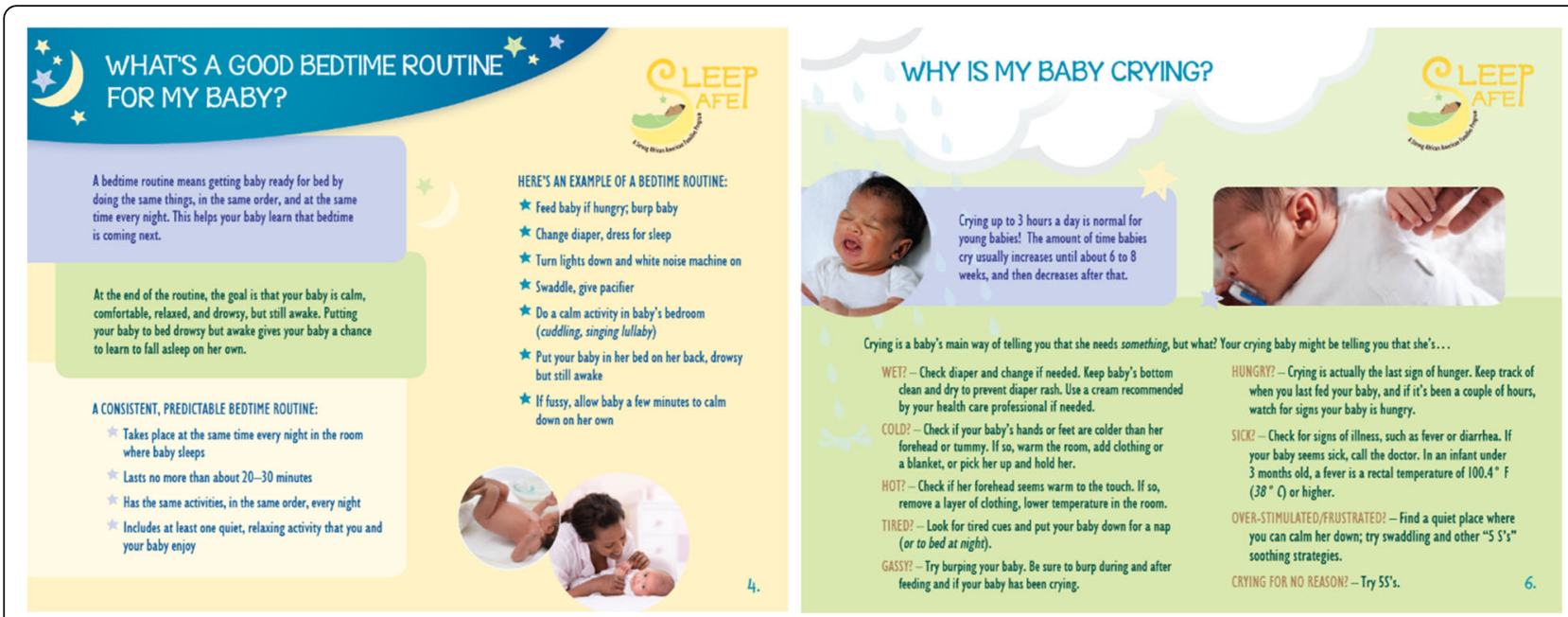

Fig. 3 Examples of sleep/soothe responsive parenting messages

Swinging, Side/Stomach Position, Sucking, and Swaddling [43]. They also received swaddle blankets and instruction and practiced swaddling their baby. We also highlighted strategies for dealing with night waking to promote selfsoothing, including allowing the infant a brief time to selfsoothe before intervening to soothe the infant.

\section{Feeding}

Intervention staff taught mothers to recognize hunger cues (rooting, mouthing, bringing hand to mouth) and fullness cues (letting go of nipple, falling asleep, turning head away, interest in other things). Expectations for typical feeding frequency during the day and night for breastfed and formula fed infants were discussed. Mothers were given education on age-appropriate bottle sizes, milk/formula volumes, use of slow-flow bottle nipples for infants under 4 months to prevent overfeeding or choking, and how to use fullness cues, rather than the amount of milk in the bottle, to determine when to terminate a feeding. Mothers were also advised that breast milk or formula is best for infants of this age, to delay the introduction of solid foods and other beverages until age 6 months, and to avoid adding infant cereal to a bottle.

\section{Playing}

Lastly, we encouraged mothers to play with their baby every day and to do tummy time with their baby for at least a few minutes each day. We also reviewed strategies to promote mothers' well-being (e.g., sleeping when baby is sleeping, reaching out to friends and family for support).

\section{Safety control}

Sleep SAAF's control group received a developmentallyappropriate child safety intervention. The home visits were designed to be equal in length and intensity to the responsive parenting intervention visits and to avoid messages that could impact responsive parenting. At 3 weeks, mothers received an extended version of the safe sleep strategies presentation from NICHD [42], which provided more detail about the Back to Sleep Campaign, SIDS facts and myths, reducing baby's risk, and the importance of good health care. In addition, information was provided about taking care of a crying baby, finding caretakers for baby, and food safety (e.g., formula and bottle handling, preparation, and storage). At the 8-week intervention visit, control group mothers received guidance on general child safety using materials from Safe Kids Worldwide [44]. This included car seat safety as well as home safety tips such as preventing falls, water safety, poison prevention, fire safety, and preventing burns.

\section{Measures}

To assess intervention impacts on the primary outcome, intermediary behavioral processes, and moderators of intervention effectiveness, data collection included measures divided into the following categories: Anthropometry, Sleep Outcomes, Infant Soothing and Feeding Outcomes, Mothers' Outcomes, Child Safety Outcomes, Stress-Support Moderators, and Demographics and Health History. As shown in Table 1, many of these measures were assessed multiple times. CRAs also rated coparent involvement in the intervention and implementation quality following the intervention sessions.

Self-report data were collected using a secure, webbased survey interface, Qualtrics, on iPads. When literacy concerns arose, CRAs read the questionnaires to mothers, who subsequently entered their answers directly into Qualtrics. Anthropometry measurements were taken and recorded using Qualtrics by the CRAs. 
Table 1 Sleep SAAF measures by time point

\begin{tabular}{|c|c|c|c|c|}
\hline \multirow[t]{2}{*}{ Construct } & \multicolumn{4}{|c|}{ Time points (child age in weeks) } \\
\hline & 1 & 3 & 8 & 16 \\
\hline \multicolumn{5}{|l|}{ Anthropometry } \\
\hline Infant weight, length, and head circumference & $x$ & $x$ & $x$ & $x$ \\
\hline Mother weight & & $x$ & $x$ & $x$ \\
\hline Father weight (if applicable) & & $x$ & $x$ & $x$ \\
\hline \multicolumn{5}{|l|}{ Sleep Outcomes } \\
\hline Mother report of infant sleep & & $x$ & $x$ & $x$ \\
\hline Mother report of own sleep & $x$ & & $x$ & $x$ \\
\hline Maternal actigraphy & & & $x$ & \\
\hline \multicolumn{5}{|l|}{ Infant Soothing and Feeding Outcomes } \\
\hline Infant soothing & & & $x$ & $x$ \\
\hline Infant temperament & & & & $x$ \\
\hline Feeding frequency & & $x$ & $x$ & $x$ \\
\hline Baby's eating behavior & & & & $x$ \\
\hline \multicolumn{5}{|l|}{ Mothers' Outcomes } \\
\hline Parenting self-efficacy & & & $x$ & $x$ \\
\hline Maternal feeding practices and beliefs & & & $x$ & $x$ \\
\hline Depressive symptoms & $x$ & & $x$ & $x$ \\
\hline Physical health & & & & $x$ \\
\hline \multicolumn{5}{|l|}{ Child Safety Outcomes } \\
\hline Safe sleep practices & $x$ & & & $x$ \\
\hline Child safety practices & & & & $x$ \\
\hline \multicolumn{5}{|l|}{ Stress-Support Moderators } \\
\hline Maternal personality & $x$ & & & \\
\hline Family background & $x$ & & & \\
\hline Financial strain/employment & $x$ & & & \\
\hline Discrimination & $x$ & & & \\
\hline Romantic relationship characteristics & $x$ & & $x$ & $x$ \\
\hline Coparent relationship characteristics & & & & $x$ \\
\hline Social support & $x$ & & & \\
\hline Family routines & & & $x$ & \\
\hline \multicolumn{5}{|l|}{ Demographics and Health History } \\
\hline Family demographics, maternal/infant health & $x$ & & & \\
\hline \multicolumn{5}{|l|}{ Intervention-Related Variables } \\
\hline Coparent involvement in intervention & & $x$ & $x$ & \\
\hline Implementation quality & & $x$ & $x$ & \\
\hline
\end{tabular}

\section{Outcomes}

The primary study outcome was a between-group comparison of infant conditional weight gain (CWG) scores from 3 weeks to 16 weeks, calculated following the method of Griffiths and colleagues [45] and described in our recent work [17]. There were several secondary weight-related outcomes that we compared between groups as well, including differences in change in infants' weight for age over time and differences between groups in infants' weight outcomes at age 16 weeks, including BMI $\mathrm{z}$ scores, weight-for-age $\mathrm{z}$ scores, and weight-forlength $\mathrm{z}$ scores.

Additionally, there were several other pre-specified outcomes assessing infant and maternal responses to intervention, including: 1) Maternal report of infant sleep (e.g., sleep duration, night awakenings); 2) Maternal sleep actigraphy (e.g., sleep duration, sleep efficiency, wakefulness); 3) Infant soothing (e.g., mothers use 
feeding for reasons other than in response to hunger); 4) Infant feeding frequency (e.g., feeding frequency, use of bottle feeding, introduction of solids); 5) Safe sleep practices; 6) Child safety practices; 7) Infant eating behavior; 8) Maternal self-efficacy; 9) Maternal feeding practices and beliefs; 10) Maternal depressive symptoms; and 11) Family routines.

\section{Sample size and power calculation}

The primary outcome for Sleep SAAF is between-group differences in CWG scores from 3 to 16 weeks. We used $\mathrm{G}$ Power 3.1.9.2 to estimate the smallest intervention effect size we could detect with $80 \%$ power, a $5 \%$ two-tailed Type 1 error rate, and two groups of 150 each (assuming $10 \%$ attrition over the course of the study) [46]. We achieved $80 \%$ power with an effect size $d$ of 0.34 . Our prior research showed an effect size of approximately 0.4 for infant conditional weight gain at 6 months [17], suggesting that we will have sufficient power in our sample to detect intervention effects.

\section{Statistical analysis plan}

All primary statistical analyses will invoke the intent-totreat paradigm, analyzing data based on randomized assignment. Missing data will be handled using fullinformation maximum likelihood methods, which use all available information to estimate parameters, making this approach more efficient and less biased than other methods when data are missing at random [47]. All models considered allow for the inclusion of relevant covariates. Covariates to be considered in refining the analyses, in addition to those described in detail in the following paragraphs, include demographic factors (e.g., maternal employment and hours worked, gestational diabetes), weight-related factors (e.g., maternal prepregnancy weight/BMI, gestational weight gain, maternal smoking), and intervention-related factors (e.g., implementation quality, coparent involvement in intervention) . We will also examine (1) infant sex as a covariate, given different growth charts for boys and girls [48] and (2) feeding mode as a covariate, given differences in weight gain between breastfed and formula-fed infants [49].

\section{Analyses for specific aim 1}

As described earlier, our primary outcome is between-group differences in conditional weight gain (CWG) scores from 3 to 16 weeks. We will calculate CWG scores following the method of Griffiths and colleagues [45], as described in our recent work [17]. Scores will be calculated as standardized residuals from the linear regression of weight for age at 16 weeks on weight for age at 3 weeks (the first intervention session), with length for age at birth and 16 weeks and infant age at the 16-week assessment entered as covariates. The CWG score represents the variation in child weight gain not explained by child age, initial length, or initial weight. A CWG score of zero represents the population mean [45]. Positive CWG scores (above the estimated regression) indicate more rapid or faster than average weight gain, while negative scores (below the estimated regression) indicate slower weight gain. We will use a linear mixed-effects model [50] to test whether the responsive parenting group and the safety control group differ in their rapid weight gain.

In addition to conditional weight gain scores, we will examine several other secondary weight outcomes. First, we will examine differences in change in infants' weight for age over time using growth curve models [51]. Specifically, we will conduct growth curve analyses using hierarchical linear modeling to test whether the responsive parenting and safety control groups differ in their rate of change in weight over time. The model will include intervention group, time of growth measure, and infant weight adjusted for gestational age. These analyses will evaluate whether the responsive parenting group shows less of an increase in weight over time compared to the safety control group. Second, we will examine differences between groups in infants' weight outcomes at age 16 weeks, including weight-for-age $\mathrm{z}$ scores, weightfor-length $\mathrm{z}$ scores, and BMI z scores. We include multiple growth outcomes because there is not one universally accepted measure for children younger than age 2 years. To compare 16-week outcomes between the responsive parenting intervention group and the safety control group, we will use linear mixed-effects models that include intervention group and infant weight at age 1 week adjusted for gestational age. These analyses will test whether the responsive parenting group and the safety control group differ in their weight outcomes at age 16 weeks.

\section{Analyses for specific aim 2}

We will examine parental behaviors (parental selfefficacy, sleep/soothing practices, feeding practices, family chaos) and infant behaviors (sleep, soothing, and feeding) targeted by the intervention that may mediate effects on infant growth. We will examine these effects in several steps. First, we will examine differences between the responsive parenting and safety control groups in these outcomes at two time points postintervention (8- and 16- weeks postpartum) using the linear mixed-effects model described above. The linear mixed-effects model will include intervention group and infant weight adjusted for gestational age. These analyses will test whether the responsive parenting group and the safety control group differ in these behaviors postintervention and will be used to identify variables for the formal tests of mediation. Second, we will examine whether parent and infant behaviors mediate infant weight outcomes. We will test these hypotheses using 
structural equation modeling. The first step in demonstrating mediation is to establish the effects on mediating and distal outcomes, as we described above. We will then specify mediators as indirect effects in a path model. Intervention condition will be dummy coded and specified as a predictor of infant and parental behaviors, which in turn predict infant weight gain and infant weight. The significance of the mediating process will be tested using the Sobel or bootstrapping methods [52].

\section{Analyses for specific aim 3}

We will examine whether individual (depressive symptoms) and contextual (socioeconomic stressors, racebased stressors, romantic relationship characteristics, coparent relationship characteristics, social support) factors at 1-week postpartum moderate program effects. These factors will be included in the analyses described in the preceding paragraphs to determine whether they moderate intervention effects on weight outcomes and parental and infant behaviors.

\section{Discussion}

Racial disparities in overweight and obesity begin early in development and persist throughout the lifespan. Early intervention efforts are needed to reduce these disparities and related comorbidities. Sleep SAAF builds on the effectiveness of our previous trials [14, 17-19] to test whether a responsive parenting program can reduce rapid weight gain among African American infants. If successful, the program would represent a promising approach to early obesity prevention that could be used in clinical practice and integrated into more comprehensive efforts to promote health and well-being among African American families.

\section{Additional file}

Additional file 1: Data and safety monitoring plan, Research maternal informed consent and parental permission for infant document. (ZIP 477 kb)

\section{Abbreviations \\ AUMC: Augusta University Medical Center; CRA: Community Research Associate; CWG: Conditional weight gain; NICHD: National Institute of Child Health and Human Development; NIDDK: National Institute of Diabetes and Digestive and Kidney Diseases; RWG: Rapid weight gain; SAAF: Strong African American Families; SIDS: Sudden Infant Death Syndrome \\ Acknowledgements \\ The authors gratefully acknowledge Jessica Smith, Megan Sperr, Tracy Anderson, the staff of the Center for Family Research, and the Sleep SAAF field staff for their assistance with this project.}

\section{Authors' contributions}

JAL and LLB led all aspects of the study concept and design. BKS, SRHB, and GHB all made substantial contributions to portions of the study design. All authors have been involved in revising the manuscript and have given final approval to the submitted version.

\section{Funding}

The project is supported by grant R01DK112874 from the National Institute of Diabetes and Digestive and Kidney Diseases (NIDDK) to Leann L. Birch and Justin A. Lavner. The funding body did not play a role in the design of the study, ongoing data collection efforts, or in writing the manuscript. The content of this article is solely the responsibility of the authors and does not necessarily represent the official views of the National Institutes of Health.

Availability of data and materials

Not applicable.

Ethics approval and consent to participate

This study was approved by the Augusta University Institutional Review Board (\#981204). Mothers completed a written form consenting to their own participation and providing permission for their infant's participation prior to being enrolled in the study (see Additional file 1.).

\section{Consent for publication}

Not applicable.

\section{Competing interests}

The authors declare they have no competing interests.

\section{Author details}

${ }^{1}$ Department of Psychology, University of Georgia, Athens, USA. ²Department of Pediatrics, Augusta University, Augusta, USA. ${ }^{3}$ Department of Psychology and Center for Family Research, University of Georgia, Athens, USA. ${ }^{4}$ Center for Family Research, University of Georgia, Athens, USA. ${ }^{5}$ Department of Foods and Nutrition, University of Georgia, Athens, USA.

Received: 28 March 2019 Accepted: 12 June 2019

Published online: 05 July 2019

\section{References}

1. Ogden CL, Carroll MD, Kit BK, Flegal KM. Prevalence of childhood and adult obesity in the United States, 2011-2012. JAMA. 2014;311(8):806-14.

2. Isong IA, Rao SR, Bind M-A, Avendaño M, Kawachi I, Richmond TK. Ethnic disparities in early childhood obesity. Pediatrics. 2018;141(1):e20170865.

3. Robert Wood Johnson Foundation. The state of obesity: better policies for a healthier America 2018. Robert Wood Johnson Foundation; 2018.

4. Woo Baidal JA, Locks LM, Cheng ER, Blake-Lamb TL, Perkins ME, Taveras EM. Risk factors for childhood obesity in the first 1,000 days: A systematic review. Am Jour Prev Med. 2016;50(6):761-79.

5. Dennison BA, Edmunds LS, Stratton HH, Pruzek RM. Rapid infant weight gain predicts childhood overweight. Obesity. 2006;14(3):491-9.

6. Roy SM, Spivack JG, Faith MS, Chesi A, Mitchell JA, Kelly A, Grant SFA, SE MC, Zemel BS. Infant BMI or weight-for-length and obesity risk in early childhood. Pediatrics. 2016;137(5):e20153492.

7. Taveras EM, Rifas-Shiman SL, Belfort MB, Kleinman KP, Oken E, Gillman MW. Weight status in the first 6 months of life and obesity at 3 years of age. Pediatrics. 2009;123(4):1177-83.

8. Baird J, Fisher D, Lucas P, Kleijnen J, Roberts H, Law C. Being big or growing fast: systematic review of size and growth in infancy and later obesity. BMJ. 2005:331:929.

9. Stettler N, Zemel BS, Kumanyika S, Stallings VA. Infant weight gain and childhood overweight status in a multicenter, cohort study. Pediatrics. 2002; 109(2):194-9.

10. Ekelund U, Ong K, Linné Y, Neovius M, Brage S, Dunger DB, et al. Upward weight percentile crossing in infancy and early childhood independently predicts fat mass in young adults: the Stockholm weight development study (SWEDES). Am J Clin Nutr. 2006:83(2):324-30.

11. Ong KK, Loos RJF. Rapid infancy weight gain and subsequent obesity: systematic reviews and hopeful suggestions. Acta Paediatr. 2006;95(8):904-8.

12. Salgin B, Norris SA, Prentice P, Pettifor JM, Richter LM, Ong KK, Dunger DB. Even transient rapid infancy weight gain is associated with higher BMI in young adults and earlier menarche. Int J Obes. 2015;39:939-44.

13. Stettler N, Kumanyika SK, Katz SH, Zemel BS, Stallings VA. Rapid weight gain during infancy and obesity in young adulthood in a cohort of African Americans. Am J Clin Nutr. 2003;77(6):1374-8.

14. Paul IM, Savage JS, Anzman-Frasca S, Marini ME, Beiler JS, Hess LB, et al. Effect of a responsive parenting educational intervention on childhood 
weight outcomes at 3 years of age: the INSIGHT randomized clinical trial. JAMA. 2018;320(5):461-8.

15. Taveras EM, Gillman MW, Kleinman K, Rich-Edwards JW, Rifas-Shiman SL. Racial/ethnic differences in early-life risk factors for childhood obesity. Pediatrics. 2010;125(4):686-95.

16. Lumeng JC, Taveras EM, Birch LL, Yanovski SZ. Prevention of obesity in infancy and early childhood: a National Institutes of Health workshop. JAMA Pediatr. 2015;169(5):484-90

17. Savage JS, Birch LL, Marini M, Anzman-Frasca S, Paul IM. Effect of the INSIGHT responsive parenting intervention on rapid infant weight gain and overweight status at age 1 year: a randomized clinical trial. JAMA Pediatr. 2016;170(8):742-9.

18. Paul IM, Savage JS, Anzman SL, Marini ME, Mindell JA, Birch LL. INSIGHT responsive parenting intervention and infant sleep. Pediatrics. 2016;138(1): e20160762.

19. Paul IM, Savage JS, Anzman SL, Beiler JS, Marini ME, Stokes JL, Birch LL. Preventing obesity during infancy: a pilot study. Obesity. 2011;19(2):353-61.

20. Eshel N, Daelmans B, Cabral de Mello M, Martines J. Responsive parenting: interventions and outcomes. Bull World Health Organ. 2006;84:992-9.

21. Adair R, Bauchner H, Philipp B, Levenson S, Zuckerman B. Night waking during infancy: role of parental presence at bedtime. Pediatrics. 1991;87(4): $500-4$.

22. Anders TF. Night-waking in infants during the first year of life. Pediatrics. 1979;63(6):860-4

23. Thompson AL, Bentley ME. The critical period of infant feeding for the development of early disparities in obesity. Soc Sci Med. 2013;97:288-96.

24. Savage JS, Birch LL. WIC mothers' depressive symptoms are associated with greater use of feeding to soothe, regardless of perceived child negativity. Pediatric Obesity. 2017;12(2):155-62.

25. Cricco-Lizza R. Infant-feeding beliefs and experiences of black women enrolled in WIC in the New York metropolitan area. Qual Health Res. 2004; 14(9):1197-210.

26. Proctor BD, Dalaker J. Poverty in the United States: 2002. US Census Bureau. Washington, DC: U.S. Government Printing Office; 2003.

27. Brody GH, Stoneman Z, Flor D. Family wages, family processes, and youth competence in rural married African American families. In Stress, coping, and resiliency in children and families. Edited by EM Hetherington and EA Blechman, Hillsdale, NJ: Lawrence Erlbaum Associates; 1996.

28. Conger RD, Wallace LE, Sun Y, Simons RL, McLoyd VC, Brody GH. Economic pressure in African American families: a replication and extension of the family stress model. Dev Psychol. 2002;38(2):179-93.

29. Benson ML, Fox GL, DeMaris A, Van Wyk J. Neighborhood disadvantage, individual economic distress and violence against women in intimate relationships. J Quant Criminol. 2003;19(3):207-35.

30. McLoyd VC. The impact of economic hardship on black families and children: psychological distress, parenting, and socioemotional development. Child Dev. 1990;61(2):311-46.

31. Ajrouch KJ, Reisine S, Lim S, Sohn W, Ismail A. Perceived everyday discrimination and psychological distress: does social support matter? Ethn Health. 2010;15(4):417-34.

32. Pieterse AL, Todd NR, Neville HA, Carter RT. Perceived racism and mental health among black American adults: a meta-analytic review. J Couns Psychol. 2012;59(1):1-9.

33. Odom EC, Vernon-Feagans L. Buffers of racial discrimination: links with depression among rural African American mothers. J Marriage Fam. 2010; 72(2):346-59.

34. McNeil S, Harris-McKoy D, Brantley C, Fincham F, Beach SR. Middle class African American mothers' depressive symptoms mediate perceived discrimination and reported child externalizing behaviors. J Child Fam Stud. 2014;23(2):381-8.

35. Brody GH, Chen YF, Kogan SM, Murry VM, Logan P, Luo Z. Linking perceived discrimination to longitudinal changes in African American mothers' parenting practices. J Marriage Fam. 2008;70(2):319-31.

36. Martin JA, Hamilton BE, Osterman MJK, Curtin SC, Mathews TJ. National Vital Statistics Reports, volume 64: births: final data for 2013. Hyattsville: National Center for Health Statistics; 2015.

37. Halpern-Meekin S, Turney K. Relationship churning and parenting stress among mothers and fathers. J Marriage Fam. 2016;78(3):715-29.

38. Anzman-Frasca S, Liu S, Gates KM, Paul IM, Rovine MJ, Birch LL. Infants' transitions out of a fussing/crying state are modifiable and are related to weight status. Infancy. 2013;18(5):662-86.
39. Paul IM, Williams JS, Anzman-Frasca S, et al. The intervention nurses start infants growing on healthy trajectories (INSIGHT) study. BMC Pediatr. 2014; 14:184.

40. Oken E, Kleinman KP, Rich-Edwards J, Gillman MW. A nearly continuous measure of birth weight for gestational age using a United States national reference. BMC Pediatr. 2003;2003(3):6.

41. Hirshkowitz M, Whiton K, Albert SM, Alessi C, Bruni O, DonCarlos L, et al. National Sleep Foundation's sleep time duration recommendations: methodology and results summary. Sleep Health. 2015;1(1):40-3.

42. National Institute of Child Health and Human Development. Babies sleep safest on their backs. Bethesda: U.S. Department of Health and Human Services; 2006

43. Karp H. The happiest baby on the block: The new way to calm crying and help your baby sleep longer [DVD]. In: US: the happiest baby Inc.; 2006.

44. Safe Kids Worldwide. Home safety tips. Retrieved from: https://www. safekids.org/tip/home-safety-tips-pdf.

45. Griffiths LJ, Smeeth L, Hawkins SS, Cole TJ, Dezateux C. Effects of infant feeding practice on weight gain from birth to 3 years. Arch Dis Child. 2009; 94(8):577-82.

46. Faul F, Erdfelder E, Lang A-G, Buchner A. G*power 3: a flexible statistical power analysis program for the social, behavioral, and biomedical sciences. Behav Res Methods. 2007:39(2):175-91.

47. Schafer JL, Graham JW. Missing data: our view of the state of the art. Psychol Methods. 2002;7(2):147-77.

48. National Center for Health Statistics. WHO growth standards are recommended for use in the U.S. for infants and children 0 to 2 years of age. Retrieved from http://www.cdc.gov/growthcharts/who_charts.htm\#The WHO Growth Charts; 2009 .

49. Ong KK, Preece MA, Emmett PM, Ahmed ML, Dunger DB. Size at birth and early childhood growth in relation to maternal smoking, parity and infant breast-feeding: longitudinal birth cohort study and analysis. Pediatr Res. 2002;52(6):863-7.

50. Laird NM, Ware JH. Random-effects models for longitudinal data. Biometrics. 1982;38(4):963-74

51. Bryk AS, Raudenbush SW. Hierarchical linear models: applications and data analysis methods. Newbury Park, CA: Sage; 1992.

52. MacKinnon DP, Lockwood CM, Hoffman JM, West SG, Sheets V. A comparison of methods to test mediation and other intervening variable effects. Psychol Methods. 2002;7(1):83-104.

\section{Publisher's Note}

Springer Nature remains neutral with regard to jurisdictional claims in published maps and institutional affiliations.

Ready to submit your research? Choose BMC and benefit from:

- fast, convenient online submission

- thorough peer review by experienced researchers in your field

- rapid publication on acceptance

- support for research data, including large and complex data types

- gold Open Access which fosters wider collaboration and increased citations

- maximum visibility for your research: over $100 \mathrm{M}$ website views per year

At $\mathrm{BMC}$, research is always in progress.

Learn more biomedcentral.com/submissions 